\title{
rTMS high frequency on the left pars operculo-orbicularis combined with orthophony improves stuttering
}

\author{
Le Guilloux J*and Megane Compper \\ Neurologist, Hospital Private North Parisian 2 avenue Charles Peguy- Sarcelles 95200 France
}

\begin{abstract}
Case report : A 43 year-old-man, right-handed, who was suffering from a severe persistent stuttering since his childhood despite orthophony was applied repetitive transcranial magnetic stimulation (rTMS) high frequency on the left pars operculo-orbicularis improves stuttering. Stimulator parameters are $10 \mathrm{~Hz}, 30$ trains of 5 seconds with an interval inter-train of 30 seconds, ten sessions, 5 days per week, every 3 months. The patient has received 1500 pulses per session.

Conclusion : rTMS stimulation combined with orthophony is a very promising approach in the treatment of persistent stuttering. Most importantly, our case may provide support for therapeutic use of rTMS to treat stuttering. More larger studies are warrented to study the efficacy of rTMS on stuttering but it's a really hope for these patients.
\end{abstract}

\section{Case report}

A 43 year-old-man, right-handed, who was suffering from a severe persistent stuttering since his childhood despite orthophony twice per week was presented in our hospital.

Since several years, he was followed for anxio-depressive syndrom by a psychologist and was treated by hypnose once per month. He has no medical past and no treatment.

Despiste this discharge, he had no significant change in speechlanguage ability. The incapacity is extremely severe, and compromises his quality of life. He isn't able to realise a sentence, no articulation.

Medical exam shows an important stuttering. Reading and conversation are impossible. Brain MRI and blood test are normal. We decide to realize repetitive transcranial magnetic stimulation on the left inferior frontal gyrus (IIFG), particularly on the left pars operculo-orbicularis (IPO), combined with orthophony to improve his stuttering. He had received 10 sessions of TMS every three months combined with orthophony twice per week.

Stuttering improved immediately after the first ten sessions of rTMS and progressively, after the second ten sessions three months later and mostly, after the third ten sessions three monts later, the patient could speak quasi-normally with a discret stuttering. rTMS treatment Sessions of rTMS treatment were delivered with a standard $70 \mathrm{~mm}$ figure-of-eight coil (PMD $70 \mathrm{pCool}$ coil), attached to a Powermag 30 Stimulator (Mag\&More, Germany). Using an MRI based frameless stereotactic neuronavigation system (Syneika One, Syneika, France), the center of the TMS coil was positioned tangential to the scalp location overlying (with the shortest distance) the left IPO. The TMS coil was oriented with the handle oriented in an anterior-toposterior and medial-to-lateral direction. The IPO target was identified according to the patient's brain surface anatomical features manually and labeled on a 3D rendering of the patient's individual T1 MRI sequence. The neuronavigation system recorded the location and after daily spatial calibration taking into account specific head fiducial points, allowing the stimulation of the exact same brain area on any new visit. Stimulator parameters are $10 \mathrm{~Hz}, 30$ trains of 5 seconds with an interval inter-train of 30 seconds. The patient has received 1500 pulses per session, ten sessions, 5 days per week, every 3 months. Motor threshold was determinated on CM1 (hand-knob area) with an EMG device. Patient was stimulated at $80 \%$ of motor threshold.

\section{Speech therapy}

The patient was administered Camperdown speech therapy 2 times per week, $45 \mathrm{~min}$ per session, and it was conducted one to one by a speech therapist.

\section{Discussion}

Stuttering is a neurodevelopmental speech disorder with a phenotype characterized by speech sound repetitions, prolongations and silent blocks during speech production. Developmental stuttering affects $1 \%$ of the population and $5 \%$ of children, predominantly in males [1].

Fluent speech production involves a dynamic organization of large-scale brain networks that coordinate cognitive, sensorimotor, and emotional systems. For stuttering patients, it is noticed neuroanatomical abnormalities in the major white matter tracts, including the left superior longitudinal fasciculus, arcuate fasciculus, corpus callosum, corticospinal, frontal aslant tracts and cortical connections with the basal-ganglia [2]. The affected tracts connect inferior frontal regions (including ventral pre-motor and motor cortex, and inferior frontal cortex and pars opercularis) with parietal (inferior parietal lobule, supramarginal and angular gyri), and temporal cortex (superior and middle temporal gyri) [2-3].

Correspondence to: Neurologist, Hospital Private North Parisian 2 avenue Charles Peguy- Sarcelles 95200 France, Email : johanleguilloux@hotmail.fr

Received: January 28, 2018; Accepted: February 16, 2018; Published: February 19, 2018 
Stuttering is characterized by an excessive recruitment of right frontal cortical areas while speaking. Right primary motor cortex, premotor cortex, supplementary motor area (SMA), pre-SMA, inferior frontal gyrus (IFG), insula, frontal and the rolandic operculum show amplified speech-related activity, particularly right rolandic operculum and precentral gyrus [4-8].

The role of right frontal hyperactivations are not clear. Several mechanisms are discussed : compensatory, causal, or maladaptive mechanisms [9].

The left and right IFG pars opercularis with their ipsilateral premotor and motor regions were decreased in the left hemisphere, but tended to be increased in the right hemisphere in adults who stutter compared to fluent speakers $[3,10]$. Thus, over-Activation right IFG is one marker of the trait of stuttering [11] and associates with underactivation of left IFG $[2,12]$. Over-activity in the right IFG may compensate for a left hemisphere deficit [13]. Speech language therapy couldn't inefficient for severe persistent stuttering although the temporary fluency enhancements caused by choral speech also temporarily normalise activity in the left IFG [14,15]. Moreover, our hypothesis is that neuromodulation treatment as repetitive transcranial magnetic stimulation (rTMS) may improve this structural and fonctionnal deficit. A single session of transcranial direct current stimulation was applied over the left inferior frontal cortex (centred on FC5 according to the 10-20 EEG electrode placement system) during $20 \mathrm{~min}$ of $1 \mathrm{~mA}$ stimulation, combined with choral speech, increases fluency speech in People who stutter. Stuttering was reduced significantly immediately after choral speech and this effect was maintained after 1 hour, at both outcome time points for the sentence-reading task, presumably due to practice, but not during the paragraph reading or conversation tasks. [16].

In our case, we suppose that rTMS on IPO modulates speech network and improves motor speech deficit. According to our knowledge, it's the first case in litterature wich use rTMS combined with orthophony to treat suttering.

\section{Conclusion}

Repetitive transcranial magnetic stimulation combined with orthophony is a very promising approach in the treatment of persistent stuttering. Most importantly, our case may provide support for therapeutic use of rTMS to treat stuttering. More larger studies are warrented to study the efficacy of rTMS on stuttering but it's a really hope for these patients.

\section{References}

1. Yairi E, Ambrose N (2013) Epidemiology of stuttering: 21 st century advances. $J$ Fluency Disord 38: 66-87. [Crossref]

2. Neef NE, Anwander A, Friederici AD (2015) The neurobiological grounding of persistent stuttering: From structure to function. Current Neurology and Neuroscience Reports 15: 63. [Crossref]

3. Kronfeld-Duenias V, Civier O, Amir O, Ezrati-Vinacour R, Ben-Shachar M (2017) White matter pathways in persistent developmental stuttering: Lessons from tractography. J Fluency Disord 16: 30078-X. [Crossref]

4. Fox PT, Ingham RJ, Ingham JC, Zamarripa F, Xiong JH, et al. (2000) Brain correlates of stuttering and syllable production. A PET performance-correlation analysis. Brain 10: 1985-2004. [Crossref]

5. Brown S, Ingham RJ, Ingham JC, Laird AR, Fox PT (2005) Stuttered and fluent speech production: an ALE meta-analysis of functional neuroimaging studies. Hum Brain Mapp 25: 105-117. [Crossref]

6. Giraud AL, Neumann K, Bachoud-Levi AC, von Gudenberg AW, Euler HA, et al (2008) Severity of dysfluency correlates with basal ganglia activity in persistent developmental stuttering. Brain Lang 104: 190-199. [Crossref]

7. Watkins KE, Smith SM, Davis S, Howell P (2008) Structural and functional abnormalities of the motor system in developmental stuttering. Brain 131 :50-59. [Crossref]

8. Belyk M, Kraft SJ, Brown S (2017) Stuttering as a trait or a state revisited: motor system involvement in persistent developmental stuttering. Eur J Neurosci. 45: 622624

9. Neef NE, Anwander A, Bütfering C, Schmidt-Samoa C, Friederici AD, et al. (2018) Structural connectivity of right frontal hyperactive areas scales with stuttering severity. Brain. 141: 191-204. [Crossref]

10. Chang SE, Horwitz B, Ostuni J, Reynolds R, Ludlow CL (2011) Evidence of left inferior frontal-premotor structural and functional connectivity deficits in adults who stutter. Cereb Cortex 21: 2507-2518. [Crossref]

11. Belyk M, Kraft SJ, Brown S (2015) Stuttering as a trait or state - An ALE metaanalysis of neuroimaging studies. The European Journal of Neuroscience 41: 275-284. [Crossref]

12. Toyomura A, Fujii T, Kuriki S (2011) Effect of external auditory pacing on the neural activity of stuttering speakers. NeuroImage 57: 1507-1516. [Crossref]

13. Preibisch C, Neumann K, Raab P, Euler HA, von Gudenberg AW, Lanfermann H, Giraud AL (2003) Evidence for compensation for stuttering by the right frontal operculum. NeuroImage 20: 1356-1364. [Crossref]

14. Wu JC, Maguire G, Riley G, Fallon J, LaCasse L, et al. (1995) A positron emission tomography $[18 \mathrm{~F}]$ deoxyglucose study of developmental stuttering. NeuroReport 6 : 501-505. [Crossref]

15. Fox PT, Ingham RJ, Ingham JC, Hirsch TB, Downs JH, (1996) A PET study of the neural systems of stuttering. Nature 382: 158-161. [Crossref]

16. Chesters J, Watkins KE, Möttönen R (2016) Investigating the feasibility of using transcranial direct current stimulation to enhance fluency in people who stutter. Brain Lang 164: 68-76. [Crossref]

Copyright: (C2018 Le Guilloux J. This is an open-access article distributed under the terms of the Creative Commons Attribution License, which permits unrestricted use, distribution, and reproduction in any medium, provided the original author and source are credited. 